\title{
Ethnographic context meets ethnographic biography: A challenge for the mores of doing fieldwork
}

Katherine E Carroll

Postdoctoral Research Fellow, Centre for Health Communication, University of Technology, Sydney, NSW, Australia

Jessica Mesman

Faculty of Arts and Social Sciences, Maastricht University, Limburg, The Netherlands

\section{ABSTRACT}

Research involves a complex network of universities, external funding bodies and industry, and researchers are increasingly faced with pressure to produce outcomes within tight temporal deadlines. This offers fresh challenges to research practice, including ethnographic research, which is traditionally based on long-term engagement in the field. This article details challenges to our ethnographic assumptions as a result of working on a highly time-bound video project in an Australian hospital. We frame the unexpected challenge to our latent ethnographic mores by forming a framework of two approaches to research: the descriptive-analytic approach and productive-reflexive approach. The article reveals how the unexpected foregrounding of our ethnographic mores played a critical role in questioning research practice. This article highlights the importance of researcher biography and the plurality and flexibility required of researchers in contemporary collaborative networks.

Keywords: handover, video-ethnography, hospital-ethnography, ethnographic norms, time, emergency department

\section{INTRODUCTION}

$\mathrm{R}$ esearch is now a complex network of universities, external funding bodies and industry (Coyle, 2009) and researchers are increasingly faced with pressure to produce outcomes within tight temporal deadlines. This offers many fresh challenges to research practice, including ethnographic research, which as a methodology is traditionally based on long-term engagement in the field (Pink, 2007). With increasing entanglement between funding bodies, fieldsites, and researchers, there are now new opportunities for the researcher to inhabit complex roles involving research, facilitation, innovation and results translation. Linkages between university-based ethnographers and industry reinforce the value and relevancy of both ethnographic research and researchers with multiple skill sets in providing answers and insights into the workings of contemporary culture. Here, through an account of our participation in a shortterm research project as ethnographers, we show how the unexpected foregrounding of our ethnographic norms played a critical role in our questioning of research practice, particularly in highlighting the plurality and flexibility required of research approaches in contemporary collaborative research. 
This paper is drawn from our experience as hospital ethnographers who, as part of 'The Handover Project' (THP), collected video data of medical and nursing handovers in an Australian Emergency Department (ED). During a handover the responsibility for the care of a patient is passed to another clinician, a process that requires detailed and accurate information exchange (Manias \& Street, 2000). It has been found that using video-footage of local handover situations enables frontline clinicians to observe and reflect on the efficacy of their own handover practices, and redesign them if necessary (Carroll, Iedema, \& Kerridge, 2008). ${ }^{1}$ The aim of THP was to develop a video-based tool that the clinicians could use for themselves to improve their own handover communication.

As part of THP research team, we collected audio-visual footage by video-recording different kinds of handovers in the ED over a period of 4 days. The comparatively short time span within which we were required to collect footage for THP, we initially thought, clashed with the normative ethnographic modes we carried as researchers who trained in a form of hospital ethnography predicated on sustained time in the field and taking time to build trust relationships with participants. This article conveys the practical tasks involved in on-the-ground problem-solving when collecting video-data of complex ED handover communication. In doing so, we reflexively foreground, utilise and challenge our own ethnographic practice assumptions in light of the practical research requirements of THP. We examine the effect of being caught within, and transitioning between two 'ways of doing' research which we heuristically label the 'descriptive-reflective' and the 'productive-reflexive' approaches. ${ }^{2}$ Our aim is not to evaluate and prioritise one approach over the other. Instead, we examine the consequences of our working within these research approaches during THP, and argue that an awareness of one's embodied ethnographer biography assists ethnographers to transition between different approaches to research work. This is important. Today's collaborative networks require researchers to embody multiple identities and enact multiple ways of doing research.

\section{VIDEO-ETHNOGRAPHY IN HOSPITAL- BASED RESEARCH}

Video-recording has been long recognised for its ability to capture the intricacy of everyday life. Video-recording is considered a strong qualitative research data-gathering tool and is used extensively in many research areas (Forsyth, Carroll, \& Reitano, 2009; Lomax \& Casey, 1998; PennEdwards, 2004; Pink, 2001; Santiano et al., 2008). ${ }^{3}$ However, using a video-camera for collecting data involves more than just 'capturing reality' (Bloustien, 2003). Images are 'potent persuaders' (Penn-Edwards, 2004, p. 266), and the creation, editing and viewing of images require elaborate preparation and attention to the representation of what is being recorded. The literature on video in qualitative research reveals detailed discussions on the modes of operation of video-cameras and raises questions of validity (Penn-Edwards, 2004); on data analysis (Heath \& Hindmarsh, 2002); the consent process (Santiano et al., 2008); on setting and background (Leinhardt \& McCormick, 1996) or on technicalities like lighting and audio-requirements (Grimshaw, 1982). ${ }^{4}$ However, the methodological challenges of video-recording involve more then lighting requirements or shooting and editing

1 This methodology was developed into the HELiCS product (Iedema \& Merrick, 2008) to assist clinicians to improve their own communication practices.

2 We would like to thank Rick Iedema for pointing out this distinction in research approaches in our initial text.

3 In their historical overview of the development of ethnography Denzin and Lincoln (1994) locate the emergence of video-recording as a data-gathering tool in their 'third moment' (1970-1986). See for a critical review of their historical framework Atkinson et al. (1999).

4 The growing number on special issues regarding video-ethnography underlines the significance of this methodology. (e.g., Bloustien, 2003; Forsyth et al., 2009; Xiao \& Mackenzie, 2004). 
procedures. This is exemplified in discussions about the meanings of the visuals and their ontological positions and epistemological choices (Bloustien, 2003; Rakic \& Chambers, 2009).

Video is increasingly common in hospitalbased research and its strengths as a method of data collection are also recognized (Lomax \& Casey, 1998; Xiao \& Mackenzie, 2004). Pertinent to this study, video has been successfully used in communication training (e.g., Guerlain, Turrentine, Adams, \& Calland, 2004; Heath, Luff, \& Sanchex Svensson, 2007), and in highly acute hospital environments such as the intensive care unit, the operating theatre (OT), and the ED (Adomat \& Hicks, 2003; Williams, Jones, Richardson, Jones, \& Richmond, 1996; Xiao, Seagull, Mackenzie, \& Klein, 2004). Yet video-methods are diverse, and the range of use gives rise to research practices that produce different types of audio-visual data. One fundamental difference is the degree of active interaction between the researchers, the video-equipment and clinician-participants. Video has been used without researcher presence. For example video has been ceiling-mounted in ED triage areas (Williams et al., 1996), in ED resuscitation bays, and over intensive care beds in order to record and analyse clinical work (Adomat \& Hicks, 2003; Xiao et al., 2004). Video has also been used with researchers present, but without the researcher actually recording the footage (Guerlain et al., 2004). These video-research projects often deem the presence of the researcher and the camera in the research environment problematic in terms of the Hawthorne effect and research 'objectivity' (Caldwell, 2005; Guerlain et al., 2004). In contrast, a more ethnographic use of video draws participants together with the researcher and the camera to form relationships (Pink, 2001). For example, researchers and participants construct and represent clinical practices actively to the video-camera (e.g., Forsyth, 2009; Lammer, 2009), whether overt or not (Lomax \&
Casey, 1998; MacDougall, 1998). In this style of videoing therefore, the camera and the presence of the researchers need to be continually negotiated directly with research participants.

In the field of health services research in Australia, researchers have worked closely with clinicians using digital, hand-held video-technology ethnographically in large tertiary hospitals. ${ }^{5}$ Instead of acting to monitor practices from afar, these ethnographic uses of video work with clinicians who, for instance, explain practices to the camera and the researcher in an expert-apprentice model (Bate and Robert, 2007). The practices explored in these projects include formal communication during ward rounds, the impact of corridor space on non-formal conversations, and the implementation of new technologies in ward environments. These research studies also provide formal occasions where researchers and clinicians view and interpret the video-footage together. Called 'video-reflexivity', this method results in new discourses about, and new ways of seeing the complex work practices involved in hospital life (Carroll, 2009; Iedema, Long, Forsyth, \& Lee, 2006; Iedema et al., 2009b). THP aimed to further develop this video-based method into a tool for clinicians to use for themselves to improve their own handover communication practices.

Handover moments have been a topic of investigation for many qualitative studies although most studies use a non-video-based means of data collection, like audio recording (e.g., Broekhuis \& Veldkamp, 2007; Chaboyer, McMurray, \& Wallis, 2010; Kerr, 2002; Manias \& Street, 2000; Sexton et al., 2004; Wilson, 2007). The video-methods used in THP feature collaborative engagement between researchers and hospital-based clinicians. It commenced with the researcher utilising ethnographic methods to identify (with clinicians) selected areas of 'everyday' handover practices to video-record, then video-recording these handover moments, followed by reflexively

For work in this area see: Carroll, 2009; Carroll et al., 2008; Forsyth 2009; Iedema \& Merrick 2008; Iedema et al. 2006, 2007, 2009a; Long, Forsyth, Carroll, \& Iedema 2006; Long, Iedema, \& Lee, 2007. 
exploring the video-footage more closely with clinicians. ${ }^{6}$ This was achieved by editing the videofootage into a selection of short clips, which were then played back to clinicians using the video reflexivity method. Thus THP follows in the tradition of the interventionist video-ethnographic and video-reflexive model. Importantly, these methods move away from taking knowledge from the field to make a repository of knowledge that may, or may not be used in practice change. ${ }^{7}$ This is an important distinction in research approaches that each entails a particular set of norms. Let us take a closer look at them.

\section{Two ways of doing ethnography}

In exploring the historical roots of ethnography, Willis (2010, p. 557) states 'ethnography is assumed to provide a deeper, more informed account gathered via long-term observations and conversations with informants in their milieu'. She goes on to argue that 'the task of ethnography is to deepen the communicative process with the aim of understanding how a particular social world is constructed, operates or changes' (p. 558). The typical results from this type of ethnography are written accounts that form a linear conversation' between the participants who have talked to the researcher who, subsequently talks to the scientific community (p. 559). For example, researchers have conducted video-ethnographic studies which involved spending extended periods of time in the field, gaining knowledge of local complexities and forming trust relationships with participants before and during video-recording. Such studies centre on comprehensive cultural knowledge accretion and the researcher acting as a voice for participants. This corresponds with what we have labelled a 'descriptive-reflective' approach. In its purest form, this approach is about researchers seeking knowledge saturation in which norms of precision, comprehensiveness, completeness, triangulation and knowledge accretion are prominent (p. 557). In sharing these results, the problem for the descriptive-reflective ethnographer is 'one of verification of observations and reliability of interpretations' (p. 556), typically solved through extended exposure to the fieldsite and participants.

In contrast, the central tenet of what we have labelled the 'productive-reflexive' approach is practice change. In the hospital context this results from the clinicians working with video data of their own work and communication to uncover for themselves the crucial aspects for practice improvements (Iedema \& Carroll, 2010, 2011). In these so-called participatory research projects practitioners do not only have a say in the research agenda but also in the outcomes of the research (Park, 1999). This approach, therefore, involves norms about the accomplishment of the task at hand, and engaging with the rapidity of cultural or practice change and data interpretation within organizations. Rather than comprehension, completeness, and the development of a final knowledge, the communication of results from ethnographic research in the productivereflexive approach is a dynamic and unpredictable flow of co-produced knowledge between researchers and practitioners (Carroll, 2009; Iedema \& Carroll, 2010). Participants are facilitated to articulate a meta-discourse about their daily work and develop tools for analysing future events as part of the research (Iedema et al., 2009b). Therefore the focus is on the development of skill rather than knowledge, that is, the skill of being able to see and talk about one's own practice in a way that is applicable to not only the 'here and now', but the future practices as well (Iedema et al., 2009b). THP's focus on communication change and the development of a tool for improving handover in

6 In line with the video-reflexive ethnography methodology we draw on Iedema (2009, p. i83) who distinguishes reflexivity from reflectivity in a clinical context by defining reflection as an individual practice of 'revisiting specific behaviours by focusing on substandard performance' and reflexivity as collaborative with a 'broad-ranging attention to everyday behaviours' such that the outcomes and effects of reflexivity are more diffuse and socially distributed in its effects.

We are aware that in practice the boundaries between these two approaches are not that neatly packaged. 
the ED rather than the collection of comprehensive evidence about handover means that THP clearly fits the characteristics of the productivereflexive approach to research. The following section discusses how we worked within the two research approaches during data collection for THP.

\section{Methodology: VideO-ReCORding FOR THP}

Using a hand-held video-camera we collected real-time video-data of handover communication practices in an ED, located within a large Australian tertiary hospital. ${ }^{8}$ The data collection period spanned 4 days, commencing Friday and finishing on Monday, thereby allowing handover data to include weekend practices. Considering this short time span we could only allocate the first day, Friday, as a non-video-recording day to introduce ourselves to clinical staff, gain consent, and familiarise ourselves with handover practices. The following 3 days we spent video-recording handovers.

There were multiple tasks and locations associated with patient care in the ED, which in turn shaped handover. We needed to video-record handover in many locations and with many teams in the ED. Nurses performed handover at different locations, for instance the nurse unit manager handover was located at the patient whiteboard in the ED, while nursing staff in 'Team A' handed over near the resuscitation bay, and another group of registered nurses, 'Team B', did their handover near the paediatric area of the ED. We also video-recorded a variety of handovers at the point of patient admission into the ED, including handover between ambulance officers and triage nurses in the ambulance bay, and between selfpresenting patients and the triage nurse at the ED triage desk.
The kind of handovers we videoed were both regular shift handovers, such as those between the night staff and day staff (time triggered) and those handovers caused by the transfer of patient care to another professional or team (event triggered). ${ }^{9}$ We recorded intra-professional handovers such as those occurring between ED doctors, and inter-professional handovers between ED doctors and nurses or between ED nurses and nurses from other departments such as the Orthopaedic Department in case of bone fractures, or the Surgery Department in case of internal trauma. We videoed not only handovers that occurred person-to-person in the hospital, but also those that involved information exchange over the phone. In most cases these handovers concerned patient referrals to other hospitals. Although we captured handovers at various locations within the ED, we focused on handovers associated with two particular types of patient trajectories: from triage into the ED, and between the ED and the Operation Theatre (OT).

While preparing ourselves to video patient trajectories and their corresponding handovers, it never occurred to us that our personal academic trajectories would be a major 'catalytic' factor for reflecting upon ethnographic norms. While both of us were thoroughly trained in the descriptivereflective approach to research, with its specific academic and behavioural norms, we now had to engage in data collection in a productive-reflexive project. One can argue that we could have thought beforehand about the research practice implications of these two different research aims and research designs. However, we argue that this requires a full awareness of one's own internalized methodological and theoretical mores. In most cases implicit aspects of one's professional identity surface only when under pressure. Therefore the incongruence we are now about to describe is not

8 The Handover Project involved four different hospital wards, each from separate hospitals. These wards included an adult intensive care unit, an ED, a paediatric intensive care unit and an acute spinal injury ward. The authors only collected data in the ED. Other project researchers were involved in data collection at the other three hospital sites. Therefore, this article reflects solely on our data collection experiences in ED.

9 For the notion of time triggered and event triggered handovers, see Broekhuis and Veldkamp (2007). 
the result of being ill-prepared but of the unanticipated impact of our 'being on the ward' and our latent normative ethnographic mores. This, as we will argue, is more a matter of ethnographic biography than of methodology. In the remainder of this article we detail our transition between the descriptive-reflective and productive-reflexive approaches and examine how our embedded ethnographic mores surfaced, and were made explicit during the data collection phase of THP, primarily as a result of the temporal limitations on our data collection period.

\section{Day one AND tWo: ENTERING the ED}

Entering an ED as a patient requires an emergency, but as a social researcher it requires among other things, the approval of an ethics committee and the support of a local gatekeeper. In our case the chief investigators had been granted Human Research Ethics Committee approval ${ }^{10}$ for the project, and had already worked collaboratively with senior ED clinician-stakeholders to negotiate our entry into the field for data collection. However, we had yet to negotiate consent with the individual clinicians who we would be video-recording during their handover communication.

On Friday morning, our first day, we were welcomed and orientated to the ED by the medical staff specialist 'Greg. ${ }^{11}$ After 10 minutes, Greg our 'inside man', returns to his work. The orientation on the ward with Greg gave us our first impression of what this particular ED was like. We saw nurses attending to documentation and talking to patients, curtains surrounding patients were closed and opened, the telephones were ringing, medical staff walked in and out of the ED as they attended to their work. Our welcoming orientation also served another purpose: the clinicians saw us 'outsiders' with the staff specialist, the 'chief insider'. ${ }^{12}$ Although at that moment most doctors and nurses had no idea who we were, being seen with the staff specialist - we hoped - assisted to legitimate our presence. Little did we know that the next time we were to meet him would be 3 days later when we were almost finished with our data collection and were about to leave the hospital.

\section{Vignette 1: Chasing signatures}

After Greg leaves we are on our own in the ED. Nobody takes any notice of us, nor feels responsible for us. What are we to do next? Introduce ourselves, hand out the consent forms, and try to gets everyone's signature on the form? After all, that was the strategy we had set out before arriving in the ED. We only had 4 days and the weight of what we had to achieve was bearing down on us. But here on the ward we felt reluctant to follow our original strategy of chasing signatures on consent forms. We are complete strangers and 'to chase signatures' after being on the ward for only 10 minutes just did not feel right.

What was it that made us reluctant to deal with the consent forms after we had entered the ward? Were we intimidated by the ED environment? No, this was not the case. We are experienced hospital-ethnographers in different kinds of critical care units and have a clinical background. As such we were not overawed by the ED environment. Therefore what was it that made us so unwilling to introduce ourselves and hand out consent forms immediately to clinicians? We propose that the source of our reluctance can be attributed to the normative structure of our ethnographer biography. We were practised at being on a ward for several days, or even weeks prior to videoing and asking for consent. Thus being in the hospital to collect data activated our 'ethnographic self' and our latent ethnographic norms such that handing out consent forms and requesting official approval to be videoed just

\footnotetext{
10 NEAF application titled National Clinical Handover Initiative, HREC Reference 17/09/19/5.08.

11 All names are pseudonyms.

12 This meeting with the chief gatekeeper was prearranged by the research team leader.
} 
10 minutes after arrival felt incompatible with our ethnographic mores. ${ }^{13}$

In the descriptive-reflective approach to research it is standard practice to include an extended period of non-video observations to develop trust relationships with those that are studied. In productive-reflexive projects, like THP, the timeframe is very different. Due to its collaborative nature, the formation of trusting relationships is not limited to the time spent in the actual fieldsite. Instead, clinicians and researchers meet months in advance while discussing the research agenda and possible means to improve practice. As a result, the visible presence of a senior clinician-stakeholder who was involved in the planning of the project during data collection becomes symbolic of the collaboration between researcher and clinician and is essential in video-recording in complex hospital environments (Santiano et al., 2008). The presence of a clinician-stakeholder provided explicit 'visual proof' of collaboration between researchers and clinicians, which, in turn, gave legitimacy to the research. What we quickly learnt, however, was that the consequences of not having a senior clinician-stakeholder present in the ED during data collection was problematic due to the absence of time to build a deep rapport with individual participants.

The significance of this was made apparent by contrasting degrees of engagement by the clinician-stakeholders 'Greg' and 'Daniel'. 'Greg', a senior ED clinician and our 'official' insider clinician-stakeholder left the ED after he gave us an introductory tour. 'Daniel', a senior anaesthetist from the OT provided sustained and regular support throughout data collection. 'Daniel' had recently seen the beneficial changes to communication in the intensive care unit as a result of video-ethnography and video reflexivity interventions and seemed more personally invested in the success of THP. Daniel regularly informed the OT clinicians about the project and emphasised the importance of clinician participation in order to gain the most value from their practice improvement project. Being seen with Daniel by other clinicians throughout the weekend assisted both THP and us as researchers gain legitimacy with participating clinicians, and this in turn helped us gain access to the locations and documentation that we needed in order to capture handover moments on video. Daniel's constant presence had positive implications for trust building, the ease with which we obtained handover data between the ED and the OT, and the ease of our participation in the ED.

\section{Familiarising ourselves with the ED}

In descriptive-analytic ethnographic studies it is common to devote the first weeks or months of one's fieldwork to a context-based orientation which enables the researcher to begin to understand the fieldsite. In productive-reflexive studies, like THP, site-orientation is also common practice. Our pre-video-recording orientation included informing ED clinicians about THP and gaining consent. We also needed to get a sense of the ED handover, who was doing what, when and where. On the basis of our 1 day of orientation we would plan our videoing strategy for the next 3 days.

\section{Vignette 2: Pole position}

\begin{abstract}
We introduce ourselves to individual clinicians and ask the nurse unit manager and some doctors what time and location the handovers are usually done. On the basis of these sources of information we decided upon ideal positions for videoing handovers within the ED. The ideal position for event triggered handovers, we conclude, is next to a large pole at the centre of the department's workstations.
\end{abstract}

13 The anthropological approach to gaining consent is at least equally about gaining a 'dynamic and continuous' negotiated consensual relationship as it is of signing a specific informed consent form (American Anthropology Association, 1998; Carnevale, 2008, p. 24). 
From here we can see the many clinicians who look at test results, phone specialist medical teams, and consult one another. The second position we decide upon is in front of the large wall-mounted white board that lists all the patients currently admitted in the ED, their bed number, time of arrival, and suspected diagnosis. It is here that time-triggered handovers will occur between day and night staff. We decide that by standing beside the pole in the middle of the ward's workstations we will be right 'on the spot' when handovers happen, and ready to record with our camera. With this strategy in mind we go home happily, looking forward to the next day.

\section{Commencing video-recording in the ED}

The next day, Saturday, we commenced videorecording. The act of video-recording made us aware of the insufficient time that we had spent observing the handovers in the ED during our 1-day orientation. Handover moments were not always self-evident. In fact they were quite discreet with many informal handovers happening concurrently. We were not always able to recognize event triggered handover moments, and when we did recognize them we were often too late to capture the handover on video. We found ourselves wondering if clinicians were doing a handover, just talking to each other about practical matters, discussing a patient, their Saturday evening plans, or a combination of all of the above. The strategy of videoing from only two locations devised after a quick conversation with a few clinicians and some hours of observation was not connecting with the complexity of communication practices in the ED. Despite allocating half of 1 day from the total of 4 days from which we were to collect data, we had greatly underestimated the importance of dedicating time to the non-video-recording phase of the temporally bound Handover Project. Yet could we have avoided these problems had we spent a considerably longer time on the ward prior to the actual videoing? Is long-term ethnography 'one-size fits all'? Before we scrutinise this in the discussion section of this article we move on to our final days of video-recording in the ED.

\section{DAY THREE AND FOUR: ONE PATIENT, MULTIPLE HANDOVERS, TEAM RESEARCH}

Our first day of video-recording was conducted in an individual shift-style manner. One of us took the video camera to record time-triggered handovers from the night to morning shift and event triggered handovers throughout the day shifts. The other researcher covered the event triggered handovers during the afternoon and videorecorded the time-triggered handovers from the evening shift to the night shift. With one camera to record data, and one researcher to build rapport and gain staff consent we soon realised that it was too complex to individually juggle the multiple factors required in video-recording handovers in the ED. We were frequently required to do three things simultaneously: introduce ourselves and then the project, ask for consent, and then immediately video the handover (c.f. Santiano et al., 2008).

Erickson and Stull (1998) describe how historically ethnography was typically a team event, often featuring husband and wife. Erickson and Stull also state that it is common to maximise time and increase coverage by scattering the team over the fieldsite, or work at different times. They also stress that at times it is useful for a research team to witness the same event or location at once. Therefore, on day two of video-recording we decided to adopt a team-based approach to data collection. This enabled us to deal with the complex and highly dynamic work environment in which we did our research and assisted us to create the time we needed to adopt a consent approach that was more closely modelled on the time-rich descriptive-reflective approach to research. In practice, this meant that one researcher acted as a scout in the ED for potential handover occurrences, while the other captured current handovers on the camera. To ensure that we were preparing the same patient trajectory, we needed to coordinate our work by regularly 
updating one another on the future movements of patients in the ED and the status of staff and patient consent. Vignette 3 demonstrates our use of the team-based approach.

\section{Vignette 3: Baby $M$}

We decide to split up in the ED. Researcher 1 goes to the triage area of the ED to try to identify potential patient admissions into the ED, while Researcher 2 spent time informing and consenting the nurse and doctor in the paediatric wing of the ED about the project. Researcher 1 identifies a patient admission involving an infant with constipation, gains consent from the infant's parents and triage staff involved, and videos handovers at the point of triage. Meanwhile inside the ED researcher 2 builds trust with, and gains consent from the paediatric nurse and paediatric doctor. As researcher 1 enters the paediatric ED from the triage area with the camera, she manages to video a smooth, seamless and fully pre-consented handover.

This vignette reveals the importance of building relationships with participants in advance of the entry of the video, and the challenges of trying to obtain smooth handover while simultaneously trying to provide participants with informed consent. By having two of us focused on just one patient, it enabled the multiple and simultaneous activity lines that make up the handover to be followed and video-recorded. Vignette $3 \mathrm{dem}$ onstrates that this was only made possible due to the simultaneous teamwork mode we adopted on day two and three of video-recording. Therefore through teamwork - two researchers simultaneously working within the ED - we generated the time that we felt we were short of. We could now scout for optimum events, gain consent from clinicians, and spread the word among clinicians about what we needed to videotape. We began to work within both the research approaches that we now embodied.

\section{DisCusSION: DOING ETHNOGRAPHIC TIME AND NORMS}

Being in a hospital setting with the aim of gathering information on handover provoked us to move automatically into our usual (descriptivereflective) ethnographic mode: a mode that, for both of us, put emphasis on trust and time. Our embedded ethnographic norms triggered us to question our research practice. We asked, 'Is it ethnography to video for only 4 days among strangers who we did not get acquainted with, or is this simply videoing moments of everyday work?' What constitutes ethnography is hotly debated (Atkinson, Coffey, \& Delamont, 1999; Tsourvakas, 1997). Certain factors such as the formation of trusting relationships, time spent in the field, and coming to terms with the complexity of the culture and environment are often indicated as determinants as to whether research is 'ethnographic' (Forsythe, 1999; Hammersley \& Atkinson, 1995). But how long should one spend in the field? Is it several months or years? Maybe even a lifetime? Although there is no agreement about the ideal length of time, almost every textbook on ethnography refers to the notion of time as a long-term engagement, for example, 'a prolonged period of investigation is essential for an ethnographer to get to know the way of a culture' (Massey, 1998, p. 3). These efforts of gaining trust, building relationships and longterm engagement are all aimed at gaining precise knowledge about the culture under study and this requires time. ${ }^{14}$

Should we consider the adage that 'ethnography needs lots of time' as anachronistic given that there are now quicker ways of connecting with people and multiple fieldsites? Some, like Jeffrey and Troman (2004), point out that long-term engagement in research fieldsites is a luxury that only doctoral students can permit since tenured academics are too busy 'to leave their job' for such a long time. Moreover, they argue, most research

14 By listing these attributes we do not intend to define what 'real' ethnography is. 
funding does not allow for spending a year or more in the field because funding bodies prefer less time-consuming methods (e.g., Savage, 2000). ${ }^{15}$ However, Jeffrey and Troman argue that these time constraining circumstances should not deprive ethnographic research of its quality. For them, ethnographic time is not only a matter of length, but also of frequency with which the sites are visited. As such, they argue, ethnographic time is not just a matter of long-term engagement but should be appropriated to the circumstances and purpose of the research project. Therefore, they propose a differentiation of ethnographic time modalities to compensate the lack of extensive time. They differentiate between three different time modes: a compressed mode, a selective intermittent mode, and a recurrent mode. Doing research in a compressed form of time involves a short period of intense ethnographic research in which researchers inhabit a research site almost permanently for anything from a few days to a month' (p. 538). The second mode of time involves a longer period of time, ranging from 3 months to 2 years. In this selective intermittent time mode the researcher visits the site frequently. These visits are selected on basis of the focus of the study while it develops (p. 540). The last form of ethnographic time, a recurrent time mode, is aimed at sampling the same temporal moments. For instances, the start and ending of a shift (p. 542). For Jeffrey and Troman one form is not superior over another. Although we concur, we should not limit our focus to quantity of time, but, instead focus on the quality of time spent in the research setting.

Ethnographic time arguably is at the basis of participant-researcher relationships, processual consent and trust, and understanding the cultural context of the research fieldsite. ${ }^{16}$ In other words, time spent, and the quality and ethical establishment of relationships with participants is a general ethnographic methodological norm, but can be enacted, as Jeffrey and Troman propose, in different ways in distinctive research projects. However, the hospital, being our 'usual' ethnographic setting, catalysed the foregrounding of our embedded ethnographic biographies and associated norms and practices, like processual consent, taking time to learn the local environment, and to form trust relationships with clinicians. Therefore, ethnographic time, in our experience, turned out to be more than a methodological issue. We already knew that the project entitled us to four research days in a fieldsite remote from our city. We also knew that we as researchers (as distinct from project managers) had not yet personally met or established relationships with key stakeholders in the field. This seemed a small methodological difference that could be rationalised intellectually. But in reality it was actually an embodied normative issue as a result of our internalised ethnographic mores. The way our ethnographic mores surfaced and made themselves explicit over the 4 days prompted us to keep asking: 'Isn't it good ethnography which builds relationships that are personal in nature?', 'How can we possibly do that in only this short time span?', 'Is what we are doing correct?' These questions are all posed as a result of the ethical imperative of the descriptive-reflective approach, while THP, instead, sought in a timely manner to intervene and draw clinicians into improving clinical and communication practices. In other words, our questions reflected the tension between our personal focus on 'we need time to get to know them' (descriptive-reflective mores) and the THP focus on 'they need to know new aspects about their practice and do something to improve it' (productive-reflexive project).

In hindsight it seems simple: our ethnographic mores belonged to another research approach that could be intellectually rationalised and

15 Sperschneider and Bagger (2003) introduce the idea of 'design-in-context' as a participant observation research strategy in an industrial setting where there is neither time nor resources for long-term engagement.

16 The ethics of ethnography and the morals of anthropology have been debated and made explicit on several occasions and platforms (e.g., AAS, 1998 code of ethics, AAA statements on ethics; Castaneda 2006; Dingwall, 1980; Goodwin, Pope, Mort, \& Smith, 2003; Murphy \& Dingwall, 2001). 
furthermore, a different set of norms should be taking their place. Yet instead of arguing that one should 'just' switch to the appropriate mode of research, we would like to argue that internalised norms are not that easy to intellectually rationalise, and moreover, that this is not a problem. One's ethnographic mores and experience are a resource that can be utilised in data collection and for us, this required us to reconcile the descriptivereflective approach with the productive-reflexive approach.

In the productive-reflexive approach, the researcher presence in the field is just one of many different points of contact between researchers, project managers and clinicians. Over time there are meetings with hospital and clinical management in which the research agenda is negotiated, introductory meetings with the clinicians on the ward, interactions between researchers and clinicians on the ward during data collection, and then subsequent discussions with clinicians during the video-reflexive analytical stage. As we were not involved in the early set-up phase and negotiation of THP with the ED clinicians, we were heavily reliant on the involvement of clinicianstakeholders throughout the short time of data collection in the ED to assist in legitimating the project with participating clinicians. In addition, we utilised a synchronous team model of data collection to assist us in creating more time for videorecording the complexity of handover moments and to enable us to draw on a consent processes that we felt comfortable with as ethnographers.

\section{Conclusion}

The Handover Project is emblematic of an innovative research partnership with a tight-turnaround time. THP was also research that was deemed by the senior clinician-stakeholders as highly relevant and as having important implications for communication, patient safety and quality care (Iedema \& Merrick, 2008; Iedema et al., 2009b). The productive-reflexive approach embodied by THP does not only involve specific norms, but also shorter timeframes. Instead of reflecting on our project as a form of 'Blitzkrieg ethnography' (Rist, 1980), Jeffrey and Troman's analysis of ethnographic time offer us a more positive perspective on the short duration in the ED by recognizing brief visits as productive ethnography.

However as researchers trained in a descriptive-reflective approach we also have to configure the demands of a project and reconcile it with our own identities and experiences. We were engaged in a productive-reflexive research project yet we brought with us ethnographer biographies and hospital-ethnography experience biased toward the descriptive-reflective approach - which has its own style of working and norms. The ethnographic norms that we had embedded within our conscious practice were initially foregrounded and 'othered' as a result of what could and could not be enacted in THP. It was at this stage that we reflexively turned to our own biography to examine this.

Roberts and Sanders (2005) demonstrate a researcher's biography to be a resource that influences research practice. Contexts, they argue, 'trigger particular mechanisms: resources, structural as well as individual, that provide individuals with the means to conduct research' (296). In our case one of the mechanisms triggered was our ethnographic biography, and it acted as both a productive and disruptive resource. Unbeknownst to us, descriptive-analytic norms were more embedded in our identity and conscious practice than we initially realised. As hospital-ethnographers, time, timing, trust and the formation of relationships with clinician-participants and with their environment are the crux of our 'practice ethics' during 'fieldwork'. We do not mean to say that very short-term visits imply a disrespectful entry into the field. On the contrary, we want to stress how compressed time required us as researchers to be reflexive about our norms, work with them to find solutions, and then transition to be able to work within the multiple research approaches required of us in a contemporary and participatory society. 


\section{ACKNOWLEDGEMENTS}

We would like to thank Rick Iedema and Dawn Goodwin for their substantial feedback on earlier versions of this paper. We would also like to thank the two anonymous reviewers for their insightful comments.

\section{References}

Adomat, R., \& Hicks, C. (2003). Measuring nursing workload in intensive care: An observational study using closed circuit video cameras. Journal of Advanced Nursing, 42, 402-412.

American Anthropology Association (AAS). (1998). Code of ethics. Access June 01, 2010, from http://www.aaanet.org/committees/ethics/ ethcode.htm

Atkinson, P., Coffey, A., \& Delamont, S. (1999). Ethnography: Post, past and present. Journal of Contemporary Ethnography, 28, 460-471.

Bate, S. P., \& Robert, G. (2007). Towards more user-centric organisational development: Lessons from a cases-study of experienced-based design. Journal of Applied Behavioural Science, 43, 41-66.

Bloustien, G. (2003). Envisioning ethnography: Exploring the meanings of the visual in research. Social Analysis, 47, 1-7.

Broekhuis, M., \& Veldkamp C. (2007). The usefulness and feasibility of a reflexivity method to improve clinical handover. Journal of Evaluation in Clinical Practice, 13, 109-115.

Caldwell, K. (2005). Non-participant observation: Using video tapes to collect data in nursing research. Nurse Researcher, 13(2), 42-54.

Carnevale, F. (2008). Using participant observation in pediatric health care settings: Ethical challenges and solutions. Journal of Child Health Care, 12, 18-32.

Carroll, K. (2009). Insider, outsider, alongsider: Examining reflexivity in hospital-based video research. International Journal of Multiple Research Approaches, 3(3), 246-263.

Carroll, K., Iedema, R., \& Kerridge, R. (2008). Reshaping ICU ward round practices using video-reflexive ethnography. Qualitative Health Research, 18, 380-390.

Castaneda, Q. E. (2006). Ethnography in the forest: An analysis of ethics in the morals of anthropology. Cultural Anthropology, 21, 121-145.
Chaboyer, W., McMurray, A., \& Wallis, M. (2010). Bedside nursing handover: A case-study. International Journal of Nursing Practice, 16, 27-34.

Coyle, T. (2009). The competition for industry research funding: How satisfied are university commercial research clients? The Australian's University Review, 51, 79-86.

Denzin, N. K., \& Lincoln, Y. S. (Eds.) (1994). Handbook of qualitative research. Thousand Oaks, CA: Sage.

Dingwall, R. (1980). Ethics and ethnography. Sociological Review, 28, 871-891.

Erickson, K., \& Stull, D. (1998). Doing team ethnography: Warnings and advice. Thousand Oaks, CA: Sage.

Forsyth, R. (2009). Distance versus dialogue: Modes of engagement of two professional groups participating in a hospital-based video ethnographic study. International Journal of Multiple Research Approaches, 3(3), 276-289.

Forsyth, R., Carroll, K., \& Reitano, P. (2009). Introduction: Illuminating everyday realities: The significance of video methods for social science and health research. International Journal of Multiple Research Approaches, 3(3), 214-217.

Forsythe, D. (1999). 'It's just a matter of common sense': Ethnography as invisible work. Computer Supported Cooperative Work, 8, 127-145.

Goodwin, D., Pope, C., Mort, M., \& Smith, A. (2003). Ethics and ethnography: An experiential account. Qualitative Health Research, 13, 567-577.

Grimshaw, A. D. (1982). Sound-image data records for research on social interaction. Sociological Methods \& Research, 11(2), 121-144.

Guerlain, S., Turrentine, B., Adams, R., \& Calland, J. (2004). Using video data for the analysis and training of medical personnel. Cognition, Technology, Work, 6, 131-138.

Hammersley, M., \& Atkinson, P. (1995). Ethnography: Principles in practice (2nd ed.). London: Routledge.

Heath, C., \& Hindmarsh, J. (2002). Analysing interaction: Video, ethnography and situated conduct. In T. May (Ed.), Qualitative research in practice (pp. 99-121). London: Sage. 
Heath, C., Luff, P., \& Sanchex Svensson, M. (2007). Video and qualitative research: Analysing medical practice and interaction. Medical Education, 41, 109-116.

Iedema, R. (2009). Creating safety by strengthening clinicians' capacity for reflexivity. British Medical Journal, 20, i83-i86.

Iedema, R., \& Carroll, K. (2010). Discourse research that intervenes in the quality and safety of care practices. Discourse and Communication, 4 , 68-86.

Iedema, R., \& Carroll, K. (2011). The 'clinalyst': Institutionalizing reflexive space to realize safety and flexible systematization in health care. Journal of Organisational Change Management, 24(2), 175-190.

Iedema, R., Forsyth, R., Georgiou, A., Braithwaite, J., \& Westbrook, J. (2007). Video research in health: Visibilizing the effects of computerizing clinical care. Qualitative Research Journal, 6(2), 15-30.

Iedema, R., Long, D., Forsyth, R., \& Lee, B. (2006). Visibilising clinical work: Video ethnography in the contemporary hospital. Health Sociology Review, 15(2), 156-168.

Iedema, R., \& Merrick, E. (2008). HELiCS: Handover-enabling learning in communication for safety. Sydney: Australian Commission on Safety and Quality in Health Care and the University of Technology.

Iedema, R., Merrick, E., Kerridge, R., Herkes, R., Lee, B., Anscombe, M., et al. (2009a). Handover - Enabling Learning in Communication for Safety (HELiCS): A report on achievements at two hospital sites. Medical Journal of Australia, 190, S133-S136.

Iedema, R., Merrick, E., Rajbhandari, D., Gardo, A., Stirling, A., \& Herkes, R. (2009b). Viewing the taken-for-granted from under a different aspect: A video-based method in pursuit of patient safety. International Journal of Multiple Research Approaches, 3(3), 290-301.

Jeffrey, B., \& Troman, G. (2004). Time for ethnography. British Educational Research Journal, 30, 535-548.

Kerr, M. P (2002). A qualitative study of shift handover practice and function from a sociotechnical perspective. Journal of Advanced Nursing, 37, 125-134.
Lammer, C. (2009). Translating experience: The creation of videos of physicians and patients in the environment of an Austrian University Hospital. International Journal of Multiple Research Approaches, 3(3), 264-275.

Leinhardt, G., \& McCormick, A. (1996). Videotape and audiotape recording in educational research. In T. Plomp \& D. P. Ely (Eds.), International encyclopaedia of educational technology (2nd ed.; pp. 568-572). Cambridge, UK: Cambridge University Press.

Lomax, H., \& Casey, N. (1998). Reordering social life: Reflexivity and video methodology. Sociological Research Online, 3, 1-31.

Long, D., Forsyth, R., Carroll, K., \& Iedema, R. (2006). The (im)possibilities of clinical democracy. Health Sociology Review, 15(5), 506-519.

Long, D., Iedema, R., \& Lee, B. B. (2007). Corridor conversations: Clinical communication in casual spaces. In R. Iedema (Ed.), Communicating hospital work: Tracing complexities in contemporary health care (pp. 182-200). Basingstoke, UK: Palgrave-Macmillan.

MacDougall, D. (1998). Transcultural cinema. Princeton, NJ: Princeton University Press. Manias, E., \& Street, A. (2000). The handover: Uncovering the hidden practices of nurses. Intensive and Critical Care Nursing, 16, 373-383.

Massey, A. (1998). 'The way we do thing around here: The culture of ethnography. Paper presented at the Ethnography and Education Conference. Oxford, 7-8 September, 1998.

Murphy, E., \& Dingwall, R. (2001). The ethics of ethnography. In P. Atkinson, A. Coffey, \& S. Delamont (Eds.), Handbook of ethnography (pp. 339-351). London: Sage.

Park, P. (1999). Knowledge and participatory research. In P. Reason \& H. Bradbury (Eds.), Handbook of action research: Participative enquiry and practice (pp. 81-90). London: Sage.

Penn-Edwards, S. (2004). Visual evidence in qualitative research: The role of videorecording. The Qualitative Report, 2, 266-277.

Pink, S. (2001). Doing visual ethnography: Images, media and representation in research. London: Sage. 
Pink, S. (2007). Introduction. In S. Pink (Ed.), Visual interventions (pp. 2-28). New York: Berghan Books.

Rakic, T., \& Chambers, D. (2009). Research with a movie camera: Visual ethnography in the field. Current Issues in Tourism, 12(3), 255-270.

Rist, R. C. (1980). Blitzkrieg ethnography: On the transformation of a method into movement. Educational Researcher, 9, 8-10.

Roberts, J., \& Sanders, T. (2005). Before, during and after: Realism, reflexivity and ethnography. The Sociological Review, 53, 294-313.

Santiano, N., Baramy, L., Young, L., Saggu, G., Cabrera, R., \& Parr, M. (2008). Problems and Solutions arising during a study of visual semantics of the medial emergency team system. Qualitative Health Research, 18(10), 1336-1344.

Savage, J. (2000). Participative observation: Standing in the shoes of others? Qualitative Health Research, 10, 324-339.

Sexton, A., Chan, C., Elliott, M., Stuart, J., Jayasuriya, R., \& Crookes, P. (2004). Nursing handovers: Do we really need them? Journal of Nursing Management, 12, 37-42.

Sperschneider, W., \& Bagger, K. (2003). Ethnographic fieldwork under industrial constraints: Toward design-in-context. International Journal of HumanComputer Interaction, 15, 41-50.
Tsourvakas, G. (1997). Multi-visual qualitative method: Observing social groups in mass media. The Qualitative Report, 3(3), 1-17. Retrieved April 17, 2011 from http://www.nova.edu/ssss/ QR/QR3-3/tsour.html

Williams, J., Jones, N., Richardson, F., Jones, C., $\&$ Richmond, P. (1996). The nursing triage process: A video review and a proposed audit tool. Journal of Accident and Emergency Medicine, 13, 398-399.

Willis, E. (2010). The problem of time in ethnographic health care research. Qualitative Health Research, 20, 556-564.

Wilson, S. (2007). Cognitive artifacts in support of medical shift handover: An in use, in situ evaluation. International Journal of Human-Computer Interaction, 22, 59-80.

Xiao, Y., \& Mackenzie, C. (2004). Introduction to the special issue on video-based research in high risk settings: Methodology and experience. Cognition, Technology, Work, 6, 127-130.

Xiao, Y. F., Seagull, J., Mackenzie, C., \& Klein, K. (2004). Adaptive leadership in trauma resuscitation teams: A grounded theory approach to video analysis. Cognition, Technology, Work, 6, 158-164.

\section{NOW AVAILABLE}

\section{Using Video in Social Sciences and Health Research}

A special issue of Multiple Research Approaches - Volume 3 Issue 3 - ii+126 pages - ISBN 978-1-921348-24-2 - December 2009

Advisory Editors: Rick ledema (University of Technology, Sydney), Christian Heath (Kings College, London) and Alexandra Juhasz (Pitzer College, Claremont CA, USA)

with

Guest Editors: Rowena Forsyth (University of New South Wales), Katherine Carroll (University of Technology, Sydney) and Paul Reitano (University of New England, Australia)

Introduction: Illuminating everyday realities: The significance of Distance versus dialogue: Modes of engagement of two video methods for social science and health research - Rowena professional groups participating in a hospital-based video ethForsyth, Katherine E Carroll and Paul Reitano nographic study - Rowena Forsyth

Video: A decolonising strategy within ethnographic research into Viewing the taken-for-granted from under a different aspect: A intercultural communication in child and family health - Julian video-based method in pursuit of patient safety - Rick ledema, Maree Grant and Yoni Luxford Eamon Thomas Merrick, Dorrilyn Rajbhandari, Alan Gardo, Anne Stirling and Robert Herkes

Authentic representation? Using video as counter-hegemony in participatory research with working-class women - Victoria Foster Outsider, insider, alongsider: Examining reflexivity in hospitalbased video research - Katherine E Carroll

Translating experience: The creation of videos of physicians and patients in the environment of an Austrian university hospital - Christina Lammer

Using video in the development and field-testing of a learning package for maternity staff: Supporting women for normal childbirth - Nicky Leap, Jane Sandall, Jane Grant, Maria Helena Bastos and Pauline Armstrong

Postscript: The significance of video research methodology for health and social science - Alexandra (Alex) Juhasz, Christian Heath and Rick ledema 